\title{
Comparison of broad range I 6S rDNA PCR and conventional blood culture for diagnosis of sepsis in the newborn: a case control study Tonje Reier-Nilsen*1, Teresa Farstad ${ }^{\dagger 1}$, Britt Nakstad ${ }^{\dagger 1,2}$, Vigdis Lauvrak ${ }^{\dagger 3}$ and Martin Steinbakk ${ }^{\dagger 3}$
}

\author{
Address: ${ }^{1}$ Department of Pediatrics Akershus University Hospital, N-1478 Lørenskog, Norway, ${ }^{2}$ University of Oslo, Akershus Faculty Division, N- \\ 1478 Lørenskog, Norway and 32Department of Microbiology Akershus University Hospital, N-1478 Lørenskog, Norway \\ Email: Tonje Reier-Nilsen* - tonjenil@hotmail.com; Teresa Farstad - tfarstad@online.no; Britt Nakstad - britt.nakstad@medisin.uio.no; \\ Vigdis Lauvrak - vigdis.lauvrak@hotmail.com; Martin Steinbakk - martin.steinbakk@ahus.no \\ * Corresponding author †Equal contributors
}

Published: 19 January 2009

BMC Pediatrics 2009, 9:5 doi:10.1186/147|-2431-9-5
Received: 19 May 2008

Accepted: 19 January 2009

This article is available from: http://www.biomedcentral.com//47I-243I/9/5

(c) 2009 Reier-Nilsen et al; licensee BioMed Central Ltd.

This is an Open Access article distributed under the terms of the Creative Commons Attribution License (http://creativecommons.org/licenses/by/2.0), which permits unrestricted use, distribution, and reproduction in any medium, provided the original work is properly cited.

\begin{abstract}
Background: Early onset bacterial sepsis is a feared complication of the newborn. A large proportion of infants admitted to the Neonatal Intensive Care Unit (NICU) for suspected sepsis receive treatment with potent systemic antibiotics while a diagnostic workup is in progress. The gold standard for detecting bacterial sepsis is blood culture. However, as pathogens in blood cultures are only detected in approximately $25 \%$ of patients, the sensitivity of blood culture is suspected to be low. Therefore, the diagnosis of sepsis is often based on the development of clinical signs, in combination with laboratory tests such as a rise in C - reactive protein (CRP). Molecular assays for the detection of bacterial DNA in the blood represent possible new diagnostic tools for early identification of a bacterial cause.
\end{abstract}

Methods: A broad range 16S rDNA polymerase chain reaction (PCR) without preincubation was compared to conventional diagnostic work up for clinical sepsis, including BACTEC blood culture, for early determination of bacterial sepsis in the newborn. In addition, the relationship between known risk factors, clinical signs, and laboratory parameters considered in clinical sepsis in the newborn were explored.

Results: Forty-eight infants with suspected sepsis were included in this study. Thirty-one patients were diagnosed with sepsis, only 6 of these had a positive blood culture. I6S rDNA PCR analysis of blinded blood samples from the 48 infants revealed 10 samples positive for the presence of bacterial DNA. PCR failed to be positive in 2 samples from blood culture positive infants, and was positive in I sample where a diagnosis of a non-septic condition was established. Compared to blood culture the diagnosis of bacterial proven sepsis by PCR revealed a $66.7 \%$ sensitivity, $87.5 \%$ specificity, $95.4 \%$ positive and $75 \%$ negative predictive value. PCR combined with blood culture revealed bacteria in $35.1 \%$ of the patients diagnosed with sepsis. Irritability and feeding difficulties were the clinical signs most often observed in sepsis. CRP increased in the presence of bacterial infection.

Conclusion: There is a need for PCR as a method to quickly point out the infants with sepsis. However, uncertainty about a bacterial cause of sepsis was not reduced by the PCR result, reflecting that methodological improvements are required in order for DNA detection to replace or supplement traditional blood culture in diagnosis of bacterial sepsis. 


\section{Background}

A large proportion of infants admitted to neonatal intensive care units (NICUs) present with signs of sepsis. In 2004,130 patients or $35.4 \%$ of all newborns admitted to the NICU at Akershus University Hospital (Ahus), Norway, were treated with broad-spectrum systemic antibiotics for suspected bacterial sepsis. However, in only a small subset of the treated patients was a pathogen actually identified. Several studies have previously tried to find a clear-cut definition of sepsis in neonates, based on a combination of clinical signs and laboratory parameters [1-3]. However, diagnosing neonatal sepsis is difficult since being exposed to known risk factors for sepsis [4-7] is not a necessity, clinical signs are often vague, and laboratory parameters are unspecific. Conventional blood culture is considered the gold standard in the etiological diagnosis of neonatal bacterial sepsis $[1,8]$. However, obtaining sufficiently large amounts of blood for culture from neonates are often difficult [9-12], and it often takes 48-72 hours to obtain a preliminary positive result. Elevation of $\mathrm{C}$ reactive protein (CRP) has been a useful marker of sepsis in many studies $[1,2]$. Initiation of broad-spectrum systemic antibiotic treatment is based only on the suspicion of sepsis since no early definitive diagnostic test is yet available. The clinician accepts some over-treatment because of the high risk of mortality if sepsis is left untreated. Two well-documented studies have shown that relevant pathogens were detected in about $25 \%$ of pediatric patients admitted to intensive care units $[13,14]$. Therefore, if no pathogenic bacterial agent is detected, the diagnosis of sepsis is based on the development of clinical signs only, often in combination with a rise in CRP $[11,15]$.

Detection of bacterial DNA in blood samples of neonates is suggested to represent a rapid and sensitive supplement to blood culture in diagnosing bacterial sepsis in neonates $[5,14,16]$. However, at present there are no standardised clinically evaluated methods available for detection of bacterial DNA in blood samples from neonates. The main aim of this study was to compare a broad range 16S rDNA PCR done on whole blood samples without prior enrichment to conventional BACTEC Peds PLUS/F blood culture for detecting bacterial DNA in blood samples from infants with suspected sepsis.

In addition, the relationship between known risk factors, clinical signs, and laboratory parameters in suspected neonatal sepsis and the diagnosis of sepsis at discharge from the NICU were explored. Since the suspicion of sepsis is based on a number of known risk factors, clinical signs and laboratory markers, it would be helpful to identify a sign or marker that could predict the diagnosis of sepsis.

\section{Methods \\ Patients}

Infants with a birth weight (BW) $>1000$ grams admitted to the NICU at Akershus University Hospital with suspected sepsis during their first week of life were included. All infants included in the study were treated with systemic antibiotics. The regional committee for medical ethics in science in Eastern Norway (REK1) approved the study and a written parental consent was obtained before inclusion.

Fifty-two infants were eligible for the study. Four of these patients were later not included in the analysis because of incomplete registration forms ( 3 infants) or missing samples for blood culture or PCR ( 1 infant).

\section{Study design}

This project was carried out as a prospective non-randomised study. The clinical and laboratory variables registered at admittance are listed in Table 1 and Table 2.

\section{Microbial analyses}

A minimum of $1 \mathrm{ml}$ full blood for conventional BACTEC Peds PLUS/F blood culture, and 1-2 ml EDTA-blood for 16S rDNA PCR were obtained by standard sterile procedures before starting general systemic antibiotic treatment. Only one blood culture bottle was routinely drawn from each patient. The bottles for culturing were immediately incubated. The EDTA-blood samples for PCR were blinded and stored in room temperature for until 72 hours, divided into plasma and cell fractions, and were then stored at $-70^{\circ} \mathrm{C}$ before analysis.

\section{$P C R$ reactions and detection limits}

PCR reactions were set up to amplify bacterial DNA using the primer 5'TGAAGAGTTTGATCATGGCTCAG combined with either primer 5'AAGGAGGTGATCCAACCG, 5'TCGTTGCGGGACTTAACC or 5'TACCGCGGCTGCTGGCA. The primers react with highly conserved regions of the bacterial 16S rRNA gene to provide PCR products of approximately 1500 basepairs (PCR 1), 1100 basepairs (PCR 2) and 500 basepairs (PCR 3), respectively [17]. All primers were produced at Eurogentec, Belgium, and are routinely used in our laboratory for 16S rRNA based identification of unknown isolates. Each PCR reaction $(50 \mu \mathrm{l})$ consisted of $1 \times$ Amplitaq Gold buffer (Applied Biosystems) supplemented with $2.5 \mathrm{U}$ Amplitaq Gold Low DNA enzyme (Applied Biosystems), $2 \mathrm{mM} \mathrm{MgCl}, 0.2 \mathrm{mM}$ dNTP (Roche) $20 \mu \mathrm{l}$ template and PCR grade water (Roche). Cycling conditions included a 5 minute denaturing step at $94^{\circ} \mathrm{C}$ followed by 30 to 40 cycles of 20 seconds at $94^{\circ} \mathrm{C}, 20$ seconds at $58^{\circ} \mathrm{C}$ and 60 seconds at $72^{\circ} \mathrm{C}$. Detection limit in $\mathrm{cfu} / \mathrm{ml}$ (colony forming units, $\mathrm{cfu}$ ) for each PCR was established in triplicate reactions of extracts from blood samples spiked with Staphylococcus aureus 
Table I: Comparison of clinical and laboratory parameters on admission in patients with sepsis (Sepsis) and patient with other noninfectious conditions (Not sepsis)

\begin{tabular}{|c|c|c|c|}
\hline Maternal parameters & Sepsis $(n=3 I)$ & Not sepsis $(n=17)$ & $\mathbf{p}$ \\
\hline Maternal fever $>38^{\circ} \mathrm{C}$ & $10 / 31$ & $5 / 17$ & 0.25 \\
\hline Maternal antibiotics & $10 / 31$ & $0 / 17$ & 0.00 \\
\hline Premature rupture of membranes & ||$/ 3 \mid$ & $4 / 17$ & 0.18 \\
\hline \multicolumn{4}{|l|}{ Infant parameters } \\
\hline Gestational age $(\mathrm{GA})<37$ weeks & $3 / 31$ & $6 / 17$ & 0.03 \\
\hline Irritability & ||$/ 3 \mid$ & $1 / 17$ & 0.02 \\
\hline Fever $>38^{\circ} \mathrm{C}$ & $7 / 31$ & $5 / 17$ & 0.23 \\
\hline Heart rate $>160$ beats per minute & $6 / 31$ & $3 / 17$ & 0.30 \\
\hline Respiratory rate $>60$ per minute & ||$/ 3 \mid$ & $5 / 17$ & 0.23 \\
\hline Apgar score at $5 \mathrm{~min}<8$ & $3 / 31$ & $7 / 17$ & 0.01 \\
\hline Feeding difficulties & $6 / 31$ & $0 / 17$ & 0.06 \\
\hline Capillary refill time $>3$ seconds & $7 / 31$ & $3 / 17$ & 0.27 \\
\hline Oxygen saturation $\left(\mathrm{SaO}_{2}\right)<88 \%$ & $6 / 31$ & $4 / 17$ & 0.27 \\
\hline $\mathrm{BE}$ (base excess) $<-5$ & $0 / 31$ & $5 / 17$ & 0.00 \\
\hline Leukocyte count $<5$ & $|/ 3|$ & $0 / 17$ & 0.64 \\
\hline Platelets $<100$ & $2 / 31$ & $1 / 17$ & 0.45 \\
\hline Blood glucose $<2,5 \mathrm{mmol} / \mathrm{l}$ & $4 / 31$ & $2 / 17$ & 0.35 \\
\hline CRP mg/l & $47.0 \pm 33.8$ & $8.5 \pm 2.5$ & 0.00 \\
\hline Highest CRP mg/l & $66.8 \pm 36.7$ & $9.1 \pm 2.7$ & 0.00 \\
\hline
\end{tabular}

(S.aureus) and Escherichia coli (E.Coli) at known concentrations $(\mathrm{cfu} / \mathrm{ml})$. The spiked blood samples were also divided in plasma and cell fraction and stored at $-70^{\circ} \mathrm{C}$. Nucleic acid was extracted from duplicates of $200 \mu \mathrm{l} \mathrm{sam-}$ ples of both fractions using the Qiagen Blood kit. DNA from each extraction was recovered with $100 \mu$ l PCR grade water (Roche). The limit of detection was set to the number of $\mathrm{cfu} / \mathrm{ml}$ of blood where all triplicates were positive. For PCR1 40 cycles of PCR could be used to detect $10^{3} \mathrm{cfu} / \mathrm{ml}$ of both E.coli and S.aureus. For PCR2 we were unable to find conditions where $10^{4} \mathrm{cfu} / \mathrm{ml}$ or less could be detected without also observing contaminants in the non-spiked controls. For PCR3 35 cycles of PCR could be used to detect $10^{4} \mathrm{cfu} / \mathrm{ml}$, however additional bands appeared when increasing the cycle numbers and dominated in samples with $10^{3} \mathrm{cfu} / \mathrm{ml}$ or less.

The EDTA blood from newborns with signs of sepsis were analysed by blinded PCR using conditions PCR 1 and PCR 3 established for the spiked blood samples. PCR results were considered positive when visible PCR products of the correct size were found in at least duplicate reactions in runs with DNA isolated from either the plasma or the cell fraction. PCR results were considered negative when 
Table 2: Comparison of clinical and laboratory parameters in patients with proven sepsis (sepsis with positive blood culture and/or detection of bacterial DNA in blood) and patients with non-proven sepsis (no bacterial agent found)

\begin{tabular}{|c|c|c|c|}
\hline Maternal parameters & Proven sepsis & Non-proven sepsis & $\mathbf{p}$ \\
\hline Maternal fever $>38^{\circ} \mathrm{C}$ & $1 / 11$ & $10 / 20$ & 0.02 \\
\hline Maternal antibiotics & $2 / 11$ & $8 / 20$ & 0.15 \\
\hline Premature rupture of membranes & $3 / 11$ & $8 / 20$ & 0.25 \\
\hline Normal vaginal delivery & $5 / 11$ & $5 / 20$ & 0.16 \\
\hline \multicolumn{4}{|l|}{ Infant parameters } \\
\hline Gestational age $(\mathrm{GA})<37$ weeks & $0 / 11$ & $2 / 20$ & 0.40 \\
\hline Irritability & $6 / 11$ & $6 / 20$ & 0.13 \\
\hline Fever $>38^{\circ} \mathrm{C}$ & $2 / 11$ & $5 / 20$ & 0.32 \\
\hline Heart rate $>160$ beats per minute & $2 / 11$ & $3 / 20$ & 0.37 \\
\hline Respiratory rate $>60$ per minute & $3 / 11$ & $8 / 20$ & 0.21 \\
\hline Apgar at $5 \min <8$ & $1 / 11$ & $3 / 20$ & 0.40 \\
\hline Feeding difficulties & $2 / 11$ & $4 / 20$ & 0.32 \\
\hline Capillary refill time $>3$ seconds & $1 / 11$ & $7 / 20$ & 0.11 \\
\hline Oxygen saturation $(\mathrm{SaO} 2)<88 \%$ & $3 / 11$ & $3 / 20$ & 0.26 \\
\hline $\mathrm{BE}<-5$ & $0 / 11$ & $0 / 20$ & 1.0 \\
\hline Leukocyte count $<5$ & $0 / 11$ & $1 / 20$ & 0.47 \\
\hline Platelets $<100$ & $2 / 11$ & $0 / 20$ & 0.12 \\
\hline Blood glucose $<2,5 \mathrm{mmol} / /$ & $0 / 11$ & $3 / 20$ & 0.25 \\
\hline CRP mg/l & $49.3 \pm 41.3$ & $42.7 \pm 29.1$ & 0.60 \\
\hline Highest CRP mg/l & $71.7 \pm 41.6$ & $70.3 .6 \pm 35.5$ & 0.92 \\
\hline
\end{tabular}

no visible PCR products of correct size were found. Results were considered inconclusive when single positive runs could not be repeated [18].

Attempts to sequence the positive PCR products were made using the PCR primers, standard Big Dye terminator cycle sequencing by capillary gel electrophoresis (Applied Biosystems). If a sequence was established, an identity match to the region between the primers was then searched in the Bio-Informatic Bacterial identification database (BiBi, Lyon France).

\section{Data analysis}

Included patients were allocated into one of two groups, $\mathrm{S}$ (Sepsis) and $\mathrm{nS}$ (not Sepsis), based on the diagnosis at discharge. The following patients in the S group were discharged from the NICU with the diagnosis of sepsis: infants with suspicion of sepsis and an elevated CRP, development of clinical signs consistent of sepsis, a marked CRP-rise, or detection of a relevant pathogen in blood culture. Patients in the $S$ group were further divided into two groups, "proven sepsis" (with detection of a pathogen bacteria in blood culture or by PCR), and "non- 
proven sepsis" (without detection of a pathogen with either method). Risk factors, clinical signs and laboratory parameters were compared between the two groups $S$ and $\mathrm{nS}$, and between "proven sepsis" and "non-proven sepsis". Nonparametric test for independent samples (the Mann-Whitney Test) was used to compare linear variables between groups. For categorical variables the Fisher exact test was used. A p-level of $<0.05$ was considered statistically significant. The statistical program SPSS version 12.01 was used for data analysis.

\section{Results}

Forty-eight infants with suspected sepsis were included in this study. At discharge from the NICU, 31 patients were diagnosed with sepsis, including both bacterial proven and non-proven sepsis, and 17 infants were discharged with a diagnosis of other non-infectious diseases. Of newborns diagnosed with sepsis, six infants had a positive blood culture and nine had a positive PCR.

\section{Comparison of I 6S rDNA PCR and blood culture}

The results are presented in Table 3 and Table 4.

Six of the infants in this study had a positive blood culture result. Two of them had mixed bacteria in their blood culture. A pathogenic bacterium was detected in blood cultures from 6 of 48 patients, counting for $19.4 \%(6 / 31)$ of the patients diagnosed with sepsis in this study. Ten patients had a positive PCR however, one was diagnosed with asphyxia and not sepsis, therefore 29.0\% (9/31) of patients were diagnosed with sepsis. Correlation between the results from PCR and blood culture was not obvious. One patient with a positive blood culture had a negative PCR result, and another patient had an inconclusive PCR result. Six patients had a positive PCR in spite of a negative blood culture. Compared to blood culture the diagnosis of bacterial sepsis in the newborn by PCR revealed $66.7 \%$ sensitivity, $87.5 \%$ specificity, $95.4 \%$ positive and $75 \%$ negative predictive value. Altogether, PCR and/or blood culture detected bacteria in $35.5 \%$ (11/31) of the patients with the diagnosis of sepsis. In our study, compared to the diagnosis of sepsis, PCR had 29.0\% sensitivity, $94.1 \%$ specificity, $90 \%$ positive and $44.4 \%$ negative predictive values.

\section{Risk factors, clinical signs and laboratory parameters in $S$ (sepsis) versus $\mathrm{nS}$ (not sepsis)}

Results are presented in Table 1.

Known risk factors $[1,19]$ such as maternal fever with temp. $>38^{\circ} \mathrm{C}$ at delivery and ruptured membranes $>12$ hours before delivery were not significantly higher in the group with sepsis. Neither did discolouration of amniotic fluid, instrumental intervention during birth or Apgar score of $<7$ at $1 \mathrm{~min}$. differ significantly between the two groups (data not shown in Table 1). Apgar scores $<8$ at 5 min and infants with gestational ages $<37$ weeks were significant higher in the non-septic group. Clinical signs of sepsis, such as fever in the newborn (defined as rectal temp. $>38^{\circ} \mathrm{C}$ ), and tachycardia (defined as heart rate $>$ 160 beats per minute), did not correlate significantly with either of the two groups. Furthermore, respiratory signs seemed to be particularly unspecific, since tachypnoea with respiratory rate $(\mathrm{RR})>60 / \mathrm{min}$., abnormal respiratory pattern, oxygen saturation $\left(\mathrm{SaO}_{2}\right)<88 \%$ and abnormal thoracic x-ray (data not shown), did not correlate with either of the two groups. Irritability and feeding difficulties seemed to be the only clinical signs to be trusted in our study when diagnosing sepsis in the newborn. Infants in the not sepsis group presented more often with base excess $<-5$ on admittance to the NICU. Patients in the sepsis group had mean CRP concentrations of 47.0

Table 3: Comparison of broad range 16 S rDNA and conventional Bactec blood culture

\begin{tabular}{llcr}
\hline & Number of patients & Broad Range I6 S rDNA PCR & Negative \\
\hline Sepsis & & $2 *$ & 4 \\
\hline Bactec + & $6 \#$ & 20 & 5 \\
\hline Bactec - & 25 & & 0 \\
\hline Not sepsis & & 0 & 1 \\
\hline Bactec + & 0 & 16 & 1
\end{tabular}

\# Culture from one patient grew four organisms (Klebsiella spp, Escherichia coli, a viridans Streptococcus and Staphylococcus aureus), culture from another patient grew two organisms (an unnamed viridans Streptococcus and Streptococcus gordomitis). Both had a positive PCR-result and were diagnosed with sepsis based on additional clinical and laboratory findings.

* One of these patients had an inconclusive PCR. 
Table 4: Microbiological results of Broad Range 16 S rDNA and conventional Bactec blood culture

\begin{tabular}{ll}
\hline Broad Range I6 S rDNA PCR & Conventional Bactec blood culture \\
\hline Positive & beta-haemolytical Streptococcus gr B \\
\hline Positive & Negative \\
\hline Positive & beta-haemolytical Streptococcus gr B \\
\hline Inconclusive & Staphylococcus lugduensis \\
\hline Positive & Streptococcus gordomitis and an unnamed viridans streptococcus (Mix) \\
\hline Positive/Haemophilus parainfluenzae & Negative \\
\hline Positive & Negative \\
\hline Staphylococcus aureus & Negative \\
\hline Positive & viridans streptococcus \\
\hline Negative & Klebsiella, Escherichia coli, Staphylococcus aureus and viridans streptococcus (Mix) \\
\hline Positive & Negative \\
\hline
\end{tabular}

(confidence interval (CI) 13.2-80.8) $\mathrm{mg} / \mathrm{L}$ at admittance to the NICU, and 66.8 (CI 30.1-103.5) $\mathrm{mg} / \mathrm{L}$ as highest CRP during treatment. The non-sepsis group had mean CRP concentrations of 8.5 (CI 6-11) $\mathrm{mg} / \mathrm{L}$ at admittance to the NICU, and 9.1 (CI 6.4-11.8) $\mathrm{mg} / \mathrm{L}$ as highest CRP during treatment.

\section{Risk factors, clinical signs and laboratory parameters in "bacterial proven sepsis" versus "non-proven sepsis" Results are presented in Table 2.}

Maternal fever at delivery was more commonly seen in infants in whom a pathogenic agent was not detected. Although instrumental intervention, discolouration of amniotic fluid and a low Apgar score tended to be overrepresented in infants with non-proven sepsis, no other risk factors analysed discriminated significantly between the two groups. Capillary filling time $>3 \mathrm{sec}$. together with respiratory rate $>60$ breaths per min. were observed more often in non-proven sepsis, while irritability was seen more often in infants with proven sepsis, although none of these findings were significant. No laboratory parameters analysed differed significantly between the two groups, but an abnormal platelet level seemed to be more common in infants with proven sepsis.

\section{Discussion}

Comparison of I6S rDNA PCR and blood culture for detecting bacteria in newborns with signs of sepsis

In the present study the diagnosis of bacterial sepsis in the newborn by PCR revealed $66.7 \%$ sensitivity, $87.5 \%$ specificity, $95.4 \%$ positive and $75 \%$ negative predictive value. While neonatal sepsis was diagnosed in 31 out of the 48 patients enrolled in the study, a pathogenic bacterium was detected in the blood culture of only $19.4 \%$ of these patients. With the molecular method of broad range $16 \mathrm{~S}$ rDNA PCR, the detection of bacteria improved to $29.0 \%$. As the total number of patients was low this difference did not obtain statistical significance. Based on the criteria used for the diagnosis of sepsis, these two methods combined had a sensitivity of $35.5 \%$.

Six patients tested positive for broad range bacterial PCR but had negative blood cultures. Five of these six patients were diagnosed with sepsis. The blood cultures may have been negative due to inadequate amount of blood drawn for optimal detection of bacteria [20-22]. Kellogg et al. [23-25] found that low-level bacteraemia $(<10 \mathrm{cfu} / \mathrm{ml})$ is far more common (up to $68 \%$ ) in paediatric patients than previously believed. They concluded that it is necessary to collect up to $4.5 \%$ of the patient's blood volume (approximately $4 \mathrm{ml} / \mathrm{kg}$ ) in at least two blood cultures to detect low concentrations of pathogens in the blood. However, as neonates are very sensitive to even small losses of blood, collecting more than 1-2 ml of blood is not an option for this group of patients. With the chosen PCR 
procedure, we observed a detection limit of $10^{3}-10^{4} \mathrm{cfu} /$ $\mathrm{ml}$ in triplicate extracts of spiked blood samples, not allowing detection of low level bacteraemia. In one patient, blood culture was positive (S.aureus) with a concordant negative PCR result. Another patient had a coagulase-negative Staphylococcus in blood culture but an inconclusive PCR at both 35 and 40 cycles. Both of these patients were considered as having proven sepsis and the result could reflect the presence of a low level of live bacteria. Even if improving the detection limit, low level bacteraemia $(<10 \mathrm{cfu} / \mathrm{ml})$ in neonates will be difficult to identify by any method based on detection of bacterial DNA or growth. To our knowledge, there are no standardised, clinically evaluated tests available for the detection of pathogenic nucleic acid in blood samples of neonates. One available PCR based test for detection of pathogenic DNA in blood of patients with suspected sepsis is developed by Roche, the LightCycler SeptiFast system. The test detects a total of 25 pathogenic bacteria and fungi in blood samples, is standardised and commercially available in Europe. However, it is not evaluated for neonates, and a volume of blood of $3 \mathrm{ml}$ is required.

Jordan et al $[14,26,27]$ showed a higher level of agreement between the two methodologies when preincubation was performed before PCR testing. They used 200-500 microl. EDTA-fullblood preincubated at $37^{\circ} \mathrm{C}$ for 5 hours before PCR-testing, and found 96\% sensitivity, 99.4\% specificity, and $88.9 \%$ positive and $99.8 \%$ negative predictive values for PCR compared with the culturing of $0.5-1.0 \mathrm{ml}$ full blood with BACTEC 9240. However, a drawback with this procedure is that only live bacteria, able to grow in blood culture bottles will be detected. In our study we omitted the enrichment step and this might explain the difference between the two methods compared to what was reported by Jordan et al $[12,23,27]$. We can not exclude that the six positive PCR-results without concordant culture-positive samples could also result from contamination. However, since five of these patients ended up with the diagnosis of sepsis based on clinical judgements and a rise in CRP, contamination seems less likely.

\section{Risk factors, clinical signs and laboratory parameters}

The World Health Organization (WHO) has suggested simple clinical criteria for the diagnosis of sepsis [28]. These criteria are based on studies in children from Ethiopia, The Gambia, Papua New Guinea and The Philippines, less than 91 days of age, who were examined because of complaints indicating possible infection. These criteria can not be easily adapted to developed countries where infants seek earlier medical attention, while symptoms are still vague. In our study, irritability in the newborn was the clinical sign observed most often $(p=0.02)$ in infants with the diagnosis of sepsis. The absence of the other clinical criteria suggested by WHO could be explained by the small number of patients with serious bacterial illness in our study [29]. Maternal fever during labour $(p=0.02)$ was more common in infants with non-proven sepsis, which may be explained by the fact that mothers with fever at delivery were more often given prophylactic antibiotic therapy. CRP is the most commonly used marker for identifying neonates with sepsis $[2,15]$. It has previously been suggested that serial elevated CRP levels are more appropriate than a single CRP measurement in diagnosing sepsis [3]. Previously, authors have operated with different cut off points for CRP in the diagnosis of neonatal clinical septicemia $[2,3]$. In this study, we did not operate with any clear cut off points in CRP before starting treatment. In view of these statements, it seems quite unlikely that neonates in this study with serial normal CRP levels e.g. $<10 \mathrm{mg} / \mathrm{L}$, did have sepsis.

\section{Conclusion}

Different medical conditions may mimic signs of sepsis in newborns, especially stress during birth. In the present study, irritability, feeding difficulties and a marked rise in CRP were important in establishing the diagnosis of sepsis in the newborn. 16S rDNA PCR method used in this study increased the sensitivity in detecting bacterial DNA in newborns with signs of sepsis, although not significantly. PCR has potential as a method for earlier detection of bacteria but this technology needs to be further developed and improved. Blood culture is irreplaceable at present, since pure isolates are essential for antimicrobial drug susceptibility testing.

\section{Competing interests}

The authors declare that they have no competing interests.

\section{Authors' contributions}

TRN, TF, BN, and MS were responsible for the study design. VL modified, validated and performed the PCR analysis. TRN was responsible for the clinical study implementation. All authors participated in writing and/or reviewing of this manuscript.

\section{Acknowledgements}

We are grateful for the assistance of Hege Smith and Tom Øystein Jonassen, from the Department of Microbiology, in establishing the I6S rDNA PCR.

We will also thank the nurses on the NICU at Akershus University Hospital, for helping to include patients in the study.

\section{References}

I. Gerdes JS: Clinicopathologic approach to the diagnosis of sepsis. Clinics in Perinatology I99I, I8:36I-38I.

2. Chiesa C, Pellegrini G, Panero A, Osborn JF, Signore F, Assumma M, Pacifico L: C-reactive protein, interleukin-6, and procalcitonin in the immediate postnatal period: influence of illness severity, risk status, antenatal and perinatal complications, and infection. Clin Chem 2003, 49:60-8. 
3. Benitz WE, Han MY, Madan A, Ramachandra P: Serial serum Creactive protein levels in the diagnosis of neonatal infection. Pediatrics 1998, 102:E4I.

4. Thomas RE, Baker P: A cost-outcome description of the septic work-up for bacterial infection in neonates in a tertiary care hospital. Intl J of Technology Assessment in Health Care 1995, II:II-25.

5. Laforgia N, Coppola B, Carbone R, Grassi A, Mautone A, lolascon A: Rapid detection of neonatal sepsis using polymerase chain reaction. Acta Paediatr 1997, 86:1097-1099.

6. Boyer KM, Gotoff SP: Strategies for chemoprophylaxix of GBS early-onset infections. Antibiot Chemother 1985, 35:267-280.

7. Cheon-Lee E, Amstey MS: Compliance with the Centers for Disease Control and Prevention antenatal culture protocol for preventing group B streptococcal neonatal sepsis. Am J Obstet Gynecol 1998, 179:77-79.

8. Washington JA II, Isltrup DM: Blood cultures: issues and controversies. Reviews of Infectious Diseases 1986, 8:792-802.

9. Jacobs RF, Sowell MK, Moss M, Fiser DH: Septic shock in children: bacterial etiologies and temporal relationships. Pediatr Infect Dis J 1990, 9:196-200.

10. GJ Richardson DK, McCormck MC, Workman K, Goldmann DA: Score for Neonatal Acute Physiology: a physiologic index for neonatal intensive care. Pediatrics 1993, 91:617-23.

II. Saez-Llorenz X, Vargas S, Guerra F, Coronado L: Applications of new sepsis definitions to evaluate outcome of pediatric patients with severe systemic infections. Pediatr Infect Dis J 1995, 14:557-56|.

12. Connel TG, Rele M, Cowley D, Buttery JP, Curtis N: How reliable is a negative blood culture result? Volume of blood submitted for culture in routine practice in a children's hospital. Pediatrics 2007, I 1 9:89|-896.

13. Kaditis AG, O'Marcaigh AS, Hable Rhodes K, Weaver AL, Henry NK: Yield of positive blood cultures in pediatric oncology patients by a new method of blood culture collection. Pediatr Infect Dis J 1996, 15:615-620.

14. Jordan JA, Durso MB, Butchko AR, Jones KG, Brozanski BS: Evaluating the near-term infant for early onset sepsis: progress and challenges to consider with 16rDNA polymerase chain reaction testing. J Mol Diagn 2006, 8:357-363.

15. Chiesa C, Panero A, Osborn JF, Simonetti AF, Pacifico L: Diagnosis of neonatal sepsis: a clinical and laboratory challenge. Clin Chem 2004, 50:279-87.

16. Silveira RC, Schlabendorff M, Procianoy RS: Predictive value of SNAP and SNAP-PE for neonatal mortality. J Pediatr (Rio J) 200I, 77:455-60.

17. Baker GC, Smith JJ, Cowan DA: Review and re-analysis of domain-specific 16S primers. I Microbiol Methods 2003, 55:54I-55.

18. Heininger A, Binder M, Ellinger A, Pfisterer J, Botzenhart K, Unertl K, Döering G: Effect of comprehensive validation of the template isolation procedure on the reliability of bacteraemia detection by a 16S r RNA gene PCR. Clin Microbiol Infect 2004, 10:452-458.

19. Cerase PA: Neonatal sepsis. J Perinat Neonatal Nurs 1989, 3:48-57.

20. Franciosi RA, Favara BE: A single blood culture for confirmation of the diagnosis of neonatal septicemia. Am J Clin Pathol 1972, 57:215-219.

21. Isaacman DJ, Karasic RB, Reynolds EA, Kost SI: Effect of number of blood cultures and volume of blood on detection of bacteriemia in children. J Pediatr 1996, I 28:190-195.

22. Scelonka RL, Chai MK, Yoder BA, Hensley D, Brockett RM, Ascher DP: Volume of blood required to detect common neonatal pathogens. J Pediatr 1996, I 29:275-278.

23. Kellogg JA, Ferrentino FL, Liss J, Shapiro SL, Bankert DA: Justification and implementation of a policy requiring two blood cultures when one is ordered. Lab Med 1994, 25:323-330.

24. Kellogg JA, Ferrentino FL, Goodstein MH, Liss J, Shapiro SL, Bankert DA: Frequency of low-level bacteriemia in infants from birth to two months of age. Pediatr Infect Dis J 1997, 16:38I-385.

25. Kellogg JA, Manzella JP, Bankert DA: Frequency of low-level bacteriemia in children from birth to fifteen years of age. J Clin Microbiol 2000, 38(6):2।8I-2। 85 .

26. Jordan JA, Durso MB: Comparison of I6sRNA gene PCR and BACTEC 9240 for detection of neonatal bacteriemia. J Clin Microbiol 2000, 38(7):2574-2578.
27. Jordan JA, Dueso MB: Real-time polymerase chain reaction for detecting bacterial DAN directly from blood of neonates being evaluated for sepsis. J Mol Diagn 2005, 7:575-58I.

28. Clinical prediction of serious bacterial infections in young infants in developing countries: The WHO Young Infants Study Group. Pediatr Infect Dis J 1999, I 8:S23-3I.

29. Vergnano S, Sharland M, Kazembe P, Mwansambo C, Heath PT: Neonatal sepsis: an international perspective. Arch Dis Child Fetal Neonatal Ed 2005, 90:F220-4.

\section{Pre-publication history}

The pre-publication history for this paper can be accessed here:

http://www.biomedcentral.com/1471-2431/9/5/prepub
Publish with Bio Med Central and every scientist can read your work free of charge

"BioMed Central will be the most significant development for disseminating the results of biomedical research in our lifetime. "

Sir Paul Nurse, Cancer Research UK

Your research papers will be:

- available free of charge to the entire biomedical community

- peer reviewed and published immediately upon acceptance

- cited in PubMed and archived on PubMed Central

- yours - you keep the copyright

Submit your manuscript here:

http://www.biomedcentral.com/info/publishing_adv.asp
BiolMedcentral 